\title{
Construction of Time-Space Structure Model of Deep Stope and Stability Analysis
}

\author{
Zhijie Wen*, Yunliang Tan, Zuozhen Han, Fanbao Meng \\ State Key Laboratory of Mining Disaster Prevention and Control Co-founded by Shandong Province \\ and the Ministry of Science and Technology, Shandong University of Science and Technology, \\ Qingdao, Shandong 266590, China
}

Received: 22 May 2016

Accepted: 20 June 2016

\begin{abstract}
To quantitatively characterize the evolution process of disaster-causing stress fields and to analyze the whole time domain characteristics of a stope from moving to stability, we constructed the four-dimensional time-space structure model of deep stope using PFC discrete element modeling software, and embedded transducers in the goaf area to monitor overlying strata movement characteristics. Targeting the gangue in the goaf area, the compression characteristics, energy absorption characteristics, and evolution of hulking coefficient over time during compaction are analyzed under different mining conditions. Results indicate that:

1. In the first stage of development of overlying strata, an intact time-space structure model of the stope cannot be formed. This means the stope structure has not reached final mechanical equilibrium.

2. Compression of the gangue fragments is an important mechanism of energy release of key strata as the strata are ruptured. The energy absorbed by the gangue reaches the maximum when the intact time-space structure model of the stope is formed.

3. The strength of the immediate roof is directly related to the development of the stope structure.

4. The development of the time-space structure of the stope is divided into two stages, which are marked by the time point when the advance distance is equal to the width of the working face.

The above analysis can explain reasons for the delayed occurrence of dynamic disasters, laying a basis for reducing dynamic disasters.
\end{abstract}

Keywords: Time-space effect, dynamic disaster, impact load, stope structure, mechanical equilibrium

\section{Introduction}

Before mining, coal is under 3D stress equilibrium at great depths. Mining disrupts the stress equilibrium, leading to redistribution of macroscopic stress and energy fields in the 3D space of the stope. However, the evolution of stress and energy fields brings about dynamic disasters [1]. Understanding the relationship between rupture morphology of rocks surrounding the coal mine stope and the stress field is the basis for predicting and controlling impact ground pressure, water bursting in mine, coal and gas bursting, and roof collapses [2-3]. To prevent the impact of ground pressure hazards occurring in a deep working face of a coal mine [4-5], the time-space

*e-mail: sdust0532@gmail.com 
effect of stability of overlying strata in the stope should be considered in conjunction with time-space evolution characteristics of mining-induced stress field and disastercausing mechanisms. This is crucial for revealing the mining effect mechanism of coal rock dynamic disasters. The mining-induced stress field evolves as the overlying strata structure is formed. Therefore, the time-space effect of the stability of overlying strata in the stope is of major concern.

Much exploratory research has been carried out concerning the whole time domain stability of the overlying strata structure in deep stopes [6-8]. Chinese scholars detected the dynamic rupture of coal rocks in 3D space using a deep-well explosion-proof MS system and wave detector installed in a deep hole. Using microseismic location and monitoring, Jiang Fuxing divided the stope into four categories: " $\theta$ ", "o", "c," and "s" [9-10]. It should be noted that the evolution of overlying strata rupture is not only related to strata structure, but also has a strong time effect. However, very little progress has been made in this field in the past 40 years [11]. We are still uncertain about the underlying reasons for the delayed occurrence of dynamic disasters relative to mining within a specific time domain.

The formation of the overlying strata structure consists of two stages [12]: in the first stage a rupture arch is formed, that is, the overlying strata undergo the changes of "bending, rupture, and touching the gangue"; in the second stage, which is the stage of gangue compression in the goaf area, the overlying strata compress the gangue and then compact the gangue. The time-space effect of stability of the stope during these two stages remains to be studied more systematically so as to quantitatively characterize the evolution of a disaster-causing stress field. Starting from the analysis of compression characteristics of gangue in the goaf area under different mining conditions, we construct the mechanical model of the stope space as it is formed and reaches equilibrium. We hope to provide
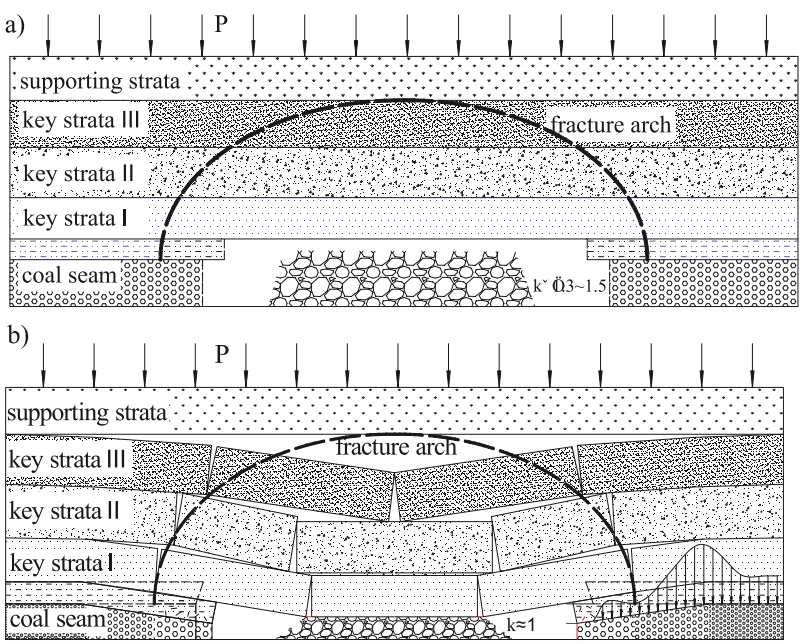

Fig. 1. Mechanical model of stope at different time points: a) Initial state of the stope, b) State of the stope after reaching stability. a reference for understanding the reasons for delayed occurrence of dynamic disasters relative to mining.

\section{Material and Methods}

\section{Construction of Four-Dimensional Time-Space Structure Model of Deep Stope}

The time-space structure model of the stope is constructed in light of the dynamic process from its initial formation to stabilization. Overlying strata that bend, rupture, and touch the gangue and then compress and compact the gangue are depicted as shown in Fig. 1. Before mining, the overlying strata of the stope are under mechanical equilibrium. As the mining advances, the overlying strata in the rupture arch ruptures one by one as they lose the support of the coal. They compress and compact the gangue fragments in the goaf area, resulting in a stable time-space structure of the stope.

Suppose the stope consists of three key strata and the stress acting on the gangue fragments in the following ways:

(1) Rupture of the n-th key stratum:

$$
F_{n}=\sum_{1}^{3} P_{n}
$$

... where $P_{n}$ is the gravity of the n-th key stratum and the overlying strata.

(2) Bending and subsidence of the overlying strata:

$$
\mathrm{F}_{4} \approx \gamma \mathrm{H}
$$

...where $\gamma$ is the bulk density of the overlying strata and $\mathrm{H}$ is mining depth.

Time-space Evolution Characteristics of the Overlying Strata Structure in the Stope in Whole Time Domain

Dynamic disasters of mines related to bearing pressure in the stope may occur during the evolution of an overlying strata structure. The human-related reasons for these disasters are lack of knowledge of the time-space evolution characteristics of mining-induced stress field and mining at the wrong time and in the wrong space. We perform simulation study of the stage of gangue compression and compaction in the goaf area of a coal mine using PFC 5.0 software. The whole time domain characteristics of the overlying strata structure are thus investigated.

\section{Mechanical Criteria for the Simulation of Gangue Compression in the Goaf Area}

The following assumptions are made for simulation: a) gangue fragments themselves will not rupture; only 


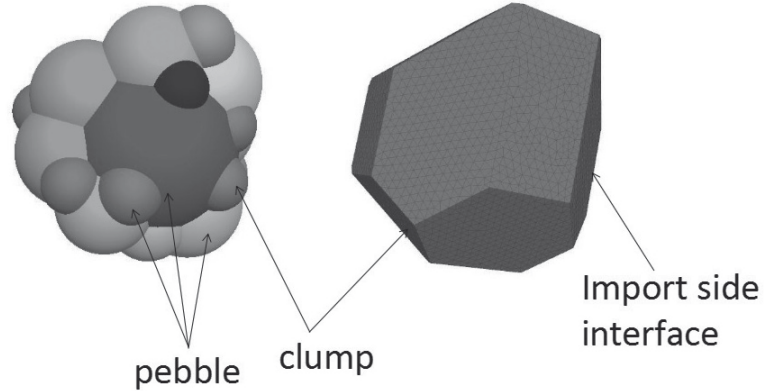

Fig. 2. Diagram showing the generation of clump importing the boundary surface.

friction, sliding, and rotation occur between the gangue fragments; b) gangue fragments are elastic material that conform to elastic theory under loading; and c) gangue fragments are subject to uniform loading.

\section{Construction of Gangue Structure Model}

In PFC 5.0 software, the clump is a rigid aggregate filled by pebbles within its boundary surface in light of the target state using the BubblePack algorithm in the software. The boundary surface of clump can be created by importing dxf/stl files (Fig. 2). But it is required that the geometrical model in the files must be directional with connected and closed boundaries; the pebbles maintain constant relative positions within the clump; no contact retrieval is carried out between the pebbles, and there is no contact force. However, the boundaries of clump may come into contact with other clumps or walls, thus creating the contact force.

\section{Simulation Schemes}

Particle size distribution of gangue in the goaf area is estimated under different mining conditions. For three grades of particle size distribution (Table 1), five simulation schemes are proposed (Table 2), and granular flow model of the gangue fragments is constructed. To better fit the real situations, two scenarios are considered for the simulation of gangue compression characteristics, namely, "same particle size distribution but different intergranular strength" and "same intergranular strength but different particle size distribution."

The model has a size of $6 \mathrm{~m} \times 2 \mathrm{~m} \times 2 \mathrm{~m}$. Using the wall in PFC 5.0 software as a model boundary, the stress of $0.5 \mathrm{MPa}, 1.0 \mathrm{MPa}, 1.5 \mathrm{MPA}$, and $10.0 \mathrm{MPa}$ is applied to the wall by servo control. Thus the rupture of the three key strata successively is simulated; the pressure exerted by the gravitational stress field to the model is also simulated at a mining depth of $600 \mathrm{~m}$. The loading at the first three levels of stress is assigned with the time step of 3,000, and for the last level of stress, cyclic loading is adopted until the model reaches final stability. To study the influence of rigidity and particle size of a clump on gangue compression under different mining conditions,
Table 1. Particle size grading of gangue fragments.

\begin{tabular}{|c|c|c|c|}
\hline No. & $\begin{array}{c}\text { Particle } \\
\text { size }(\mathrm{mm})\end{array}$ & $\begin{array}{c}\text { Particle size } \\
\text { grading }\end{array}$ & Relative size \\
\hline P1 & $200 \sim 250$ & Grade 1 & Large particle size \\
\hline P2 & $75 \sim 200$ & Grade 2 & Medium particle size \\
\hline P3 & $12.5 \sim 75$ & Grade 3 & Small particle size \\
\hline
\end{tabular}

Table 2. Simulation schemes.

\begin{tabular}{|c|c|c|c|c|}
\hline \multirow{2}{*}{$\begin{array}{c}\text { Scheme } \\
\text { number }\end{array}$} & \multicolumn{3}{|c|}{$\begin{array}{c}\text { Mass percentage of different } \\
\text { particle sizes (\%) }\end{array}$} & \multirow{2}{*}{$\begin{array}{c}\text { Rigidity } \\
(\mathrm{N} / \mathrm{m})\end{array}$} \\
\cline { 2 - 4 } & P1 & P2 & P3 & \\
\hline I & 10 & 30 & 60 & $1.05 \mathrm{e} 9$ \\
\hline II & 30 & 40 & 30 & $4.05 \mathrm{e} 9$ \\
\hline III & 50 & 30 & 20 & $6.53 \mathrm{e} 9$ \\
\hline IV & 30 & 40 & 30 & $1.05 \mathrm{e} 9$ \\
\hline V & 30 & 40 & 30 & $6.53 \mathrm{e} 9$ \\
\hline
\end{tabular}

the coefficient of friction $\mathrm{f} 1$ for the clump-clump action is set as 0.35 uniformly. The volume fraction of the initial clump is $60 \%$ of the total volume of the model (i.e., the initial volumetric expansion coefficient $\mathrm{K}$ of strata is 1.67); the coefficient of friction between clump and wall is set as 0.20 . The model thus constructed (with clump magnified by 20 times) is shown in Fig. 3 .

a)

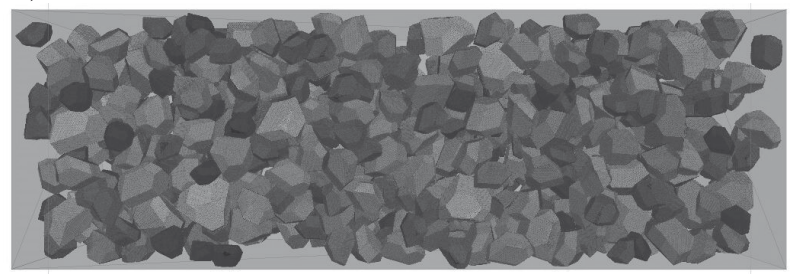

b)

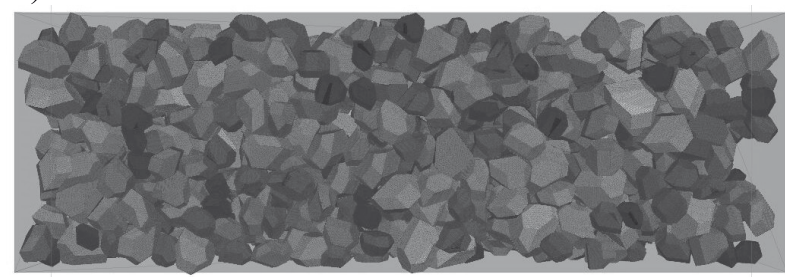

c)

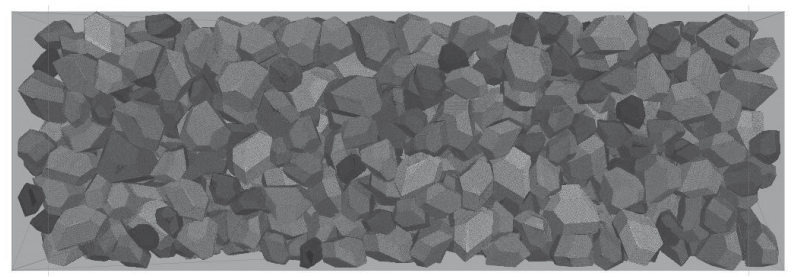

Fig. 3. Time-space model of the stope:a) Schematic diagram of scheme I; b) Schematic diagram of scheme II (IV, V); c) Schematic diagram of scheme III. 


\section{Characteristic Curve of Gangue Compaction}

The evolution of gangue compaction characteristics (volumetric expansion coefficient) in different schemes with stress and time step is shown in Fig. 4. It can be seen that:

1. As the overlying strata structure is formed, the gangue in the goaf area is gradually compacted. Macroscopically this is manifested as the ruptured overlying strata touching the gangue and continuing to subside slowly; microscopically, the porosity of the gangue decreases in the goaf area, i.e., volumetric expansion coefficient decreases gradually. As seen from the changes of volumetric expansion coefficient, it continues to decrease by $33-44 \%$ upon loading at the fourth level of stress after compression by the first three levels of stress. This indicates that gangue fragments cannot reach final stability by compression by the ruptured strata alone. During stability analysis of time-space structure of the stope, not only the obvious movement of overlying strata (rupturing and touching the gangue), but the slow movement (action of gravity field related to mining depth) also needs to be considered.

2. Schemes II, IV, and V have the same particle size distribution but different intergranular strengths. The softer the gangue (i.e., the smaller the strength of the immediate roof), the larger the variation of the volumetric expansion coefficient of the gangue fragments, and the greater the impact on stope ability. Schemes I and III-V have different particle size distributions. Given the same intergranular strength, the higher the percentage of larger gangue fragments (i.e., the larger the strength of the immediate roof), the larger the variation of the volumetric expansion coefficient of the gangue fragments and the greater the impact on stope ability.

Gangue fragments in the goaf area are compressed by the ruptured strata. Since the ruptured strata keep

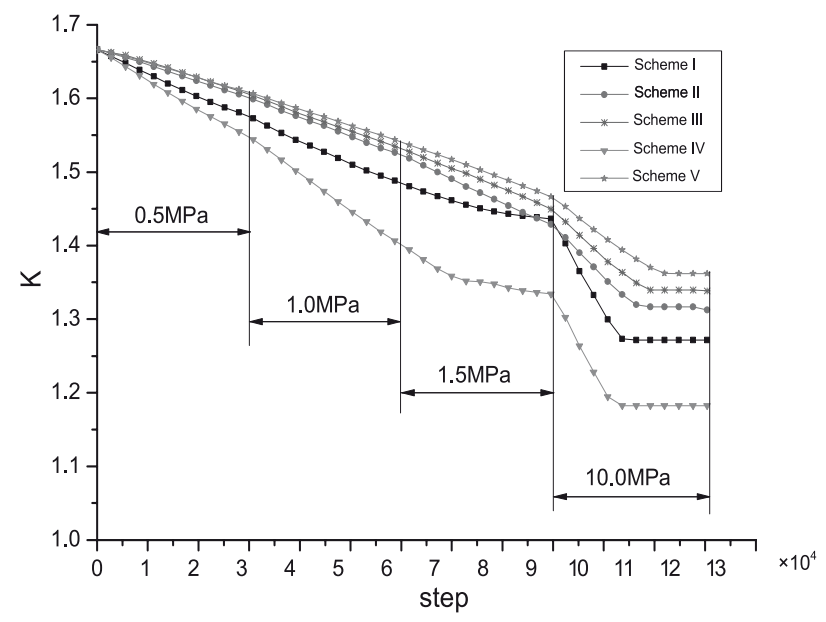

Fig. 4. Characteristic curves of gangue compaction.

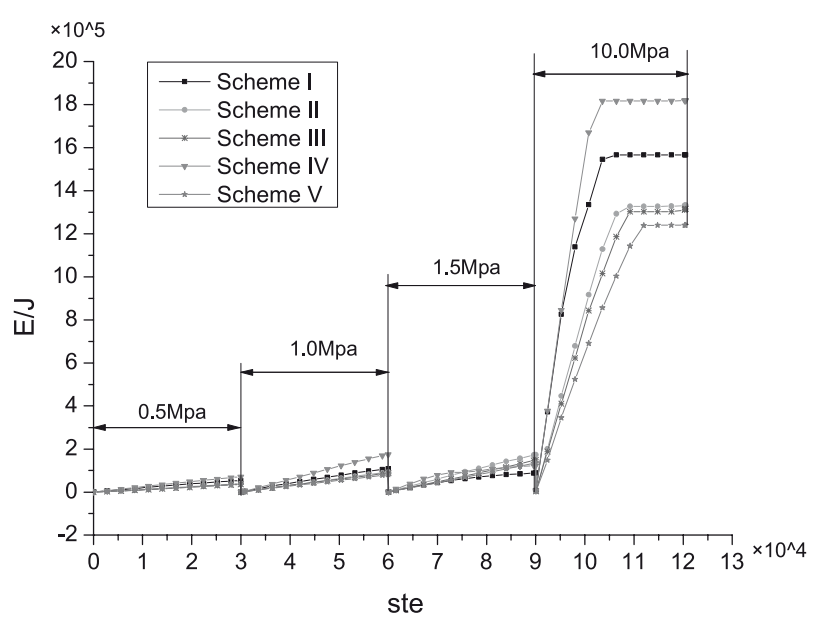

Fig. 5. Characteristic curves of energy absorption.

transferring the stress to their surroundings, the subsidence and deformation of the ruptured strata decrease. In the meantime, more energy spreads to the surrounding areas.

Characteristic curves of energy absorption with different schemes are shown in Fig. 5. It can be seen that:

(a) As the overlying strata collapse and compact the gangue, the gangue fragments absorb the energy released by the ruptured strata continually. The first key stratum ruptures and exerts pressure on the gangue, and the gangue absorbs little energy. As the second and third key strata rupture, the energy absorbed increases and finally reaches the maximum due to compression by the slow moving key strata.

(b) Schemes II, IV, and V have the same particle size distribution but different intergranular strengths. The harder the gangue, the less the energy released by compression of gangue by the ruptured key strata, and the greater the energy stored in the surrounding rocks. That is to say, mining with a hard immediate roof is associated with greater risk of dynamic disasters, and more attention should be given to mechanical stability of the stope. Schemes I and III-V have different particle size distributions, but the same intergranular strength. The larger the gangue fragments, the greater the energy absorbed during the process toward stability. This is associated with a greater roof impact hazard.

\section{Results and Discussion}

Time-Space Effect upon Rupture
of Overlying Strata

The dynamic monitoring system (DMS) for the stope was applied to detect the strata structure and movement and evolution characteristics of mining-induced stress in real-time. DMS is capable of real-time, all-around monitoring of dynamic information of overlying strata in the stope.

The experimental site was working face No. 12301 at Dongda Coal Mine, with a burial depth of $650 \mathrm{~m}$ and 


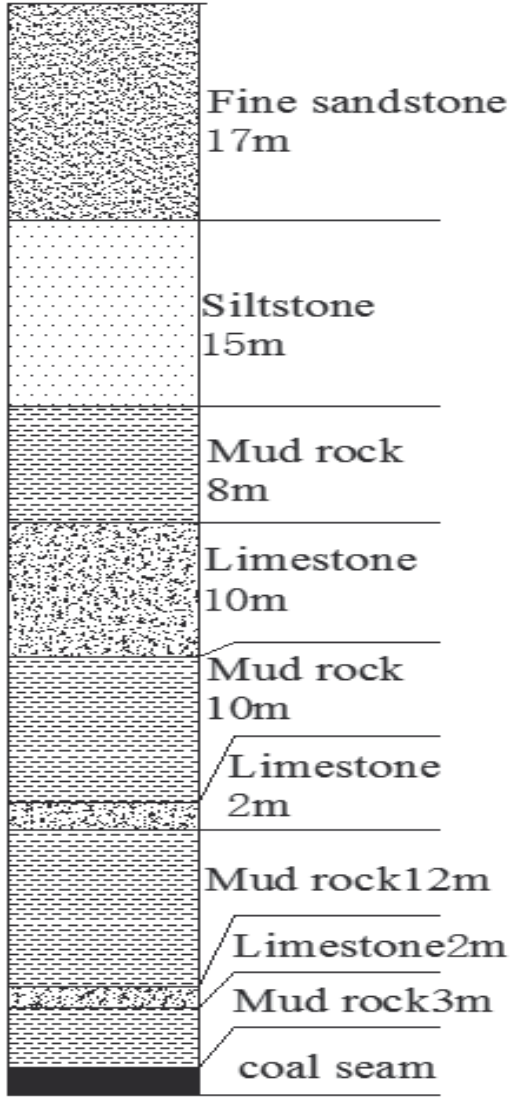

Fig. 6. Vertical profile of the working face.

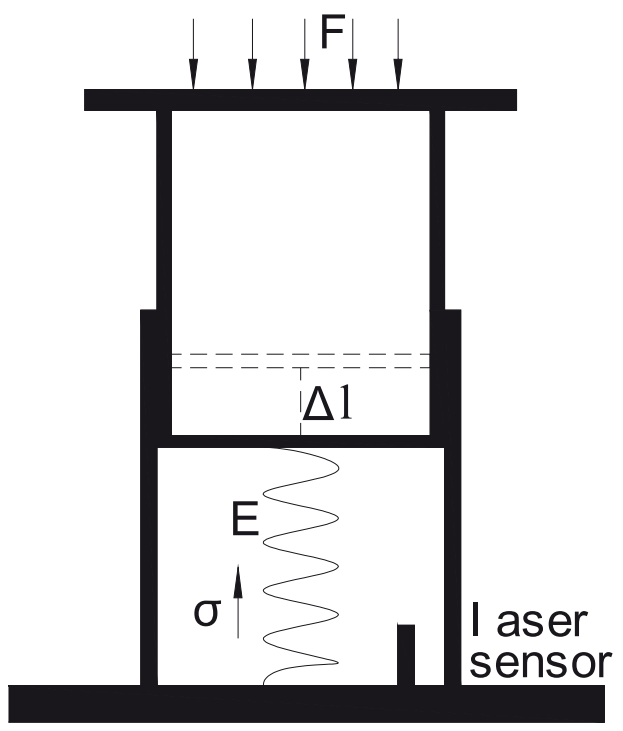

Fig. 7. Schematic diagram of the sensor.

width of $120 \mathrm{~m}$. Two measuring points were arranged. The vertical profile of the working face is shown in Fig. 6 and the testing equipment is shown in Fig. 7.

\section{Working Principle of DMS}

As the mining proceeds, the overlying strata exhibit different rupture characteristics due to the varlying

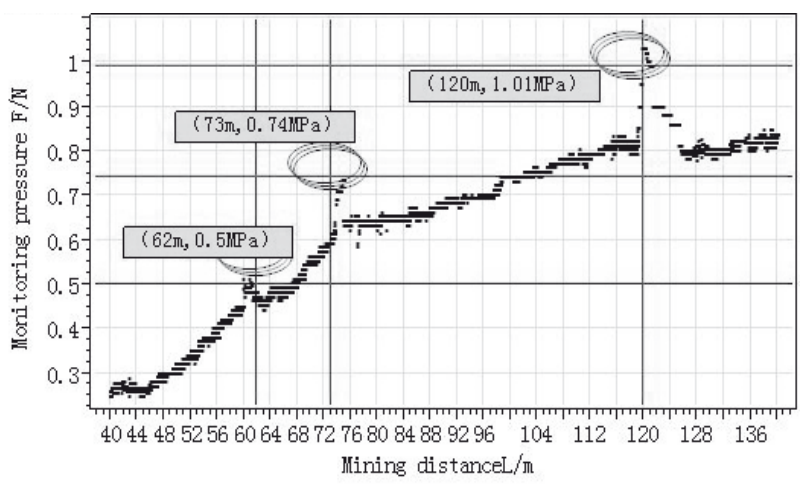

Fig. 8. Monitoring pressure data.

lithology of the overlying strata. Such changes can be divided into distinct stages over time. The bending and rupture of the overlying strata produce dynamic impact on the goaf area. DMS is effective in monitoring dynamic characteristics of stope structure as the overlying strata rupture and evolve.

\section{Recognition of Stope Stability}

The testing equipment was placed in the goaf area at an advance distance of 40 . The movement of the overlying strata during advance was monitored in real time. The curve obtained from monitoring is shown in Fig. 8, and the analysis is shown in Table 3.

As the working face advanced, the stope structure underwent the transition from formation to development and finally to stability. DMS captured three dynamic impact events and final stability of the stope. When the advance distance was smaller than the width of the working face $(120 \mathrm{~m})$, the monitoring curve showed three major fluctuations corresponding to the rupture of three key strata. Meanwhile, the ruptured strata compressed and compacted the gangue fragments in the goaf area, indicating instability of the stope. When the advance distance was larger than the width of the working face $(120 \mathrm{~m})$, the monitoring curve flattened. This indicated that the mechanical structure had reached stability. After that, no more overlying strata ruptured, while the gangue was further compressed in the goaf area.

\section{Application Prospect of Dynamic Mechanical Model of Overlying Strata Structure in Mining Engineering}

The dynamic mechanical model of overlying strata structure and its application shed new light onto the strata movement within a greater scope and under various boundary conditions. This model has high theoretical and practical value for determining the height of the diversion fissure zone, raising the mining upper limit, and predicting the impact of ground pressure and coal and gas bursting. It is especially valuable for deep mining. 
Table 3. Dynamic information of rock breaking.

\begin{tabular}{|c|c|c|c|c|c|}
\hline $\begin{array}{c}\text { Key } \\
\text { strata }\end{array}$ & $\begin{array}{c}\text { Positition of } \\
\text { rupture }\end{array}$ & $\begin{array}{c}\text { Impact load } \\
(106 \mathrm{~N})\end{array}$ & $\begin{array}{c}\text { Steady load } \\
(106 \mathrm{~N})\end{array}$ & $\begin{array}{c}\text { Scope of rupture } \\
(\mathrm{H} / \mathrm{m})\end{array}$ & Actual scope of rupture $(\mathrm{H} / \mathrm{m})$ \\
\hline $\begin{array}{c}\text { First } \\
\text { key stratum }\end{array}$ & $\begin{array}{c}\text { Advance } \\
\text { distance } 62 \mathrm{~m}\end{array}$ & 0.28 & 0.20 & 11.30 & 15 (mudstone $3 \mathrm{~m}$, limestone $2 \mathrm{~m}$, \\
mudstone $12 \mathrm{~m})$
\end{tabular}

\section{Conclusions}

1. Dynamic disasters have a time-space effect. The formation of overlying strata structure consists of two stages: in the first stage, the overlying strata bend, rupture, and touch the gangue; in the second stage, the overlying strata compress and compact the gangue. The first stage plays a leading role in the formation of overlying strata structure in the stope, while the second stage creates disaster-forming conditions. This is the major reason why dynamic disasters do not happen simultaneously with mining, but with certain delay.

2. Simulation analysis reveals that the volumetric expansion coefficient of gangue fragments varies more significantly if the gangue is soft (i.e., the strength of the immediate roof is small) with schemes having the same particle size distribution but different intergranular strengths. When the particle size distribution is different but the intergranular strength is identical, the higher the percentage of the larger gangue fragments (i.e., the greater the strength of the immediate roof), the greater the variation of the volumetric expansion coefficient of the gangue, and the greater the impact on stope stability.

3. With the same particle size distribution but different intergranular strengths, the harder the gangue in the goaf area, the less the energy released by the compression of gangue by the ruptured strata; moreover, there is greater energy stored in the surrounding rock. That is to say, mining with a hard roof is associated with higher risk of dynamic disasters. Therefore, mechanical stability of the stope structure needs to be enhanced. With different particle size distribution but the same intergranular strength, the larger size of the gangue means that more energy is absorbed during the process toward final stability. This is associated with greater roof impact hazard.

4. As the working face advances, the mechanical structure of the stope undergoes three stages, from formation to development and finally to stability. The division is made when the advance distance is equal to the width of the working face. During our experiment, DMS captured three dynamic impact events and the state of stability of the stope. On this basis, the movement characteristics of overlying strata in the stope in the whole time domain are revealed under different mining conditions.

\section{Acknowledgements}

This work was supported by the National Natural Science Foundation of China (Nos. 51304126 and 51304235), Fok Ying Tung Education Foundation (No. 141046), China Postdoctoral Science Foundation (No. 2013M541918), Shan Dong University of Science and Technology Outstanding Young Investigator Award (No. 2014JQJH105), Shandong Province Higher Educational Science and Technology Program (No. J15LH04), State Key Laboratory of Open Funds (No. SKLGDUEK1520), Tai'shan Scholar Engineering Construction Fund of the Shandong Province of China; Tai'shan Scholar Talent Team Support Plan for Advanced \& Unique Discipline Areas, and the State Key research Development Program of China (No. 2016YFC0600708-3).

\section{References}

1. JIANG Y., ZHAO Y. State of the art: investigation on mechanism, forecast and control of coal bumps in china[J]. Chinese Journal of Rock Mechanics and Engineering, 34 (11), 2188, 2015.

2. PAN J., MAO D., LAN H., WANG S.,QI Q. Study status and prospects of mine pressure bumping control technology in china[J]. Coal Science and Technology, 41 (06), 21, 2013.

3. YAO J., HE F., XU J., DOU L. Energy mechanism of rock burst and its application[J]. Journal of Central South University (Science and Technology), 40 (03), 808, 2009.

4. CAO A., LUO X., DOU L., WAND H. KING A. Experimental research on seismic wave transmission and attenuation associated with underground longwall coal mining[J]. Journal of Mining \& Safety Engineering, 28 (04), 530, 2011.

5. ZHANG C.Q., FENG X.T., ZHOU H., QIU S.L., WU W.P. A top pilot tunnel precond- -itionnning method for the prevention of extremely intense rockbursts in deep tunnels excavated by TBMS[J]. Rock Mechanics and Rock Engineering, 31 (03), 289, 2012.

6. CAI M. Influence of stress path on tunnel excavation response - numerical tool selection and modeling strategy[J]. Tunneling and Underground Space Technology, 23 (06), 618, 2008.

7. TAN Y.L., YU F.H., CHEN L. A new appoach for predictiong bedding separation of roof strata in underground coalmines. International Journal of Rock Mechanics \& Mining Sciences 61, 183, 2013.

8. TANG C.A., WANG J.M., ZHANG J.J. Preliminary engineering application of microseismic monitoring 
technique to rockburst prediction in tunneling of Jinping II Project[J]. Journal of Rock Mechanics and Geotechnical Engineering, 02 (03), 193, 2010.

9. JIANG F. Study on the spatial structure of overlying strata and its application[J]. Journal of Mining And Safety Engineering, 1, 30, 2006.

10. JIANG F., XUN L.,YANG S. Spatial fracturing progresses of surrounding rock masses in longwall face monitored by microseismic monitoring techniques[J]. Chinese Jounal of Geotechnical Engineering, 1, 23, 2003.
11. SYD S PENG. Topical areas of research needs in ground control-A state of the art review on coal ming ground control[J]. Journal of China University of Mining and Technology, 44 (01), 1, 2015.

12. WEN Z.J., M. RINNE, SONG Z., HAN Z.Z., WEN J.H. Research on Modeling of Spatial Dynamic Structural Mechanics and Spatio-temporal Evolution of Coal Mine Stopes[J]. Tehnički vjesnik - Technical Gazette 22 (03), 2015. 